http://dx.doi.org/10.18232/alhe.952

Artículos

\title{
El mercado de trabajo en el modelo agroexportador en Argentina: el papel de la inmigración
}

\section{The labor market in the agro-export model in Argentina: the role of immigration}

\author{
Nicolás Arceo ${ }^{1,2}$ iD 0000-0002-9382-6463 \\ Ana L. Fernández ${ }^{3}$ (D) 0000-0003-3616-5619 \\ Mariana L. González 1, 2, * (DD 0000-0001-9783-5343
}

\footnotetext{
${ }^{1}$ Consejo Nacional de Investigaciones Científicas y Técnicas, Buenos Aires, Argentina.

${ }^{2}$ Facultad Latinoamericana de Ciencias Sociales, Buenos Aires, Argentina.

${ }^{3}$ Universidad Nacional de General Sarmiento, Buenos Aires, Argentina.

*Correspondencia: marianagonzale@gmail.com
}

Resumen. En la segunda mitad del siglo xix la economía argentina se incorporó plenamente al mercado mundial como proveedora de materias primas de origen agropecuario, alcanzando elevadas tasas de crecimiento. Dicha expansión fue acompañada por un aumento en la demanda de mano de obra, cubierta centralmente a través de la inmigración. El objetivo del trabajo es determinar las consecuencias que tuvo la política migratoria sobre el mercado de trabajo en el periodo 1870-1930, en particular sobre los salarios reales. A partir de la caracterización del mercado laboral y del análisis de las migraciones, se concluye que los flujos migratorios determinaron a inicios del siglo xx un exceso de oferta de trabajo que repercutió negativamente sobre los salarios reales, provocando un desmejoramiento de la estructura distributiva.

Palabras clave: modelo agroexportador; mercado de trabajo; migraciones internacionales; salarios reales.

CÓMO CITAR: Arceo, N., Fernández, A. L. y González, M. L. (2019). El mercado de trabajo en el modelo agroexportador en Argentina: la función de la inmigración. America Latina en la Historia Económica, 26(3), e952. DOI: 10.18232/alhe.952

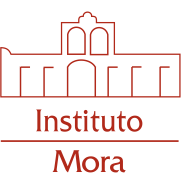


Abstract. In the second half of the 19th century, Argentina's economy was fully incorporated to the world market as a supplier of raw materials of agricultural origin achieving high economic growth rates. This expansion was accompanied by an increase in the demand for labor, which was centrally covered through immigration. The aim of this work is to assess the consequences of the migration policy carried out between 1870 and 1930 on the local labor market, particularly on real wages. Based on the characterization of the labor market and the analysis of migrations, it is concluded that migratory flows at the beginning of the twentieth century led to an excess labor supply that lowered real wages, thus worsening in the income distribution.

Key words: Agro-export model; labor market; international migrations; real wages.

JEL: N36; J43.

Recibido: 16 de enero de 2018.

Aceptado: 6 de julio de 2018.

Publicado: 1 de abril de 2019.

Organismo colaborador: Agencia Nacional de Promoción Científica y Tecnológica, Proyecto PICT-2016-3306, Argentina. Agradecimientos: a Eduardo Basualdo por los comentarios a una versión previa de este artículo.

\section{INTRODUCCIÓN}

Desde las últimas décadas del siglo xIx y hasta 1930 Argentina vivió el periodo de mayor crecimiento económico de su historia, en el marco de su plena incorporación al mercado mundial como economía proveedora de materias primas de origen agropecuario. En esos años la creciente necesidad de mano de obra de la economía fue cubierta principalmente a través de la llegada de inmigrantes, en un contexto internacional en el que se observaban grandes oleadas migratorias interoceánicas hacia los países del llamado Nuevo Mundo.

En este marco, el objetivo de este trabajo es determinar las consecuencias que tuvo la política migratoria llevada adelante por el Estado argentino durante el periodo del modelo agroexportador sobre el mercado de trabajo local, en particular sobre los salarios reales. La política migratoria en Argentina se distinguió por mantener abiertas las fronteras abiertas a lo largo de todo ese periodo, mientras que otros países receptores establecieron mayores regulaciones y restricciones, en general en respuesta a coyunturas económicas en que se incrementaba la desocupación.

El principal aporte radica en el análisis de la relación entre la evolución del salario real y el flujo migratorio durante el periodo, relación que por lo general no es abordada en la bibliografía sobre la materia. Si bien existen numerosas referencias acerca del papel del salario relativo como factor de atracción de migrantes, se encuentran escasos estudios referidos al impacto del flujo inmigratorio sobre la oferta laboral y, a través de la misma, sobre los salarios reales en la economía local (Míguez, 2001; Panettieri, 1970; Sánchez-Alonso, 2004).

Con base en este objetivo el cuerpo del trabajo se divide en tres secciones. En la primera, se describen las principales características de la evolución de la economía durante el modelo agroexportador en Argentina, es decir, en el periodo comprendido entre los años 1870 y 1930. En la siguiente, se evalúan los flujos migratorios verificados en el ámbito internacional durante ese mismo periodo, y se presentan las especificidades que presentó Argentina respecto a otros países re- 
ceptores de mano de obra. La última sección se destina a la caracterización del mercado laboral en Argentina durante esos años, y al análisis de los efectos de la política migratoria llevada adelante por el Estado argentino, en particular su efecto sobre los niveles salariales.

Finalmente, en las conclusiones del trabajo se esbozan, a modo de hipótesis, los posibles impactos que tuvo la política migratoria llevada a cabo durante el modelo agroexportador sobre el devenir posterior de la economía argentina, en particular durante la etapa de industrialización por sustitución de importaciones. En definitiva, se trata de indagar acerca de los efectos de largo plazo de una política inmigratoria, considerada como uno de los pilares sobre el que se construyó la Argentina moderna.

\section{El MOdELO AGROEXPORTADOR EN ARgENTINA: 1870-1930}

El periodo comprendido entre las últimas décadas del siglo xIX y la crisis internacional de la década de 1930, conocido en la historia económica argentina como el periodo del modelo agroexportador, fue la etapa de mayor crecimiento económico de este país. La consolidación de un patrón de crecimiento basado en la inserción en el mercado mundial a través de la exportación de productos de origen agropecuario, para los cuales la nación contaba con condiciones agroecológicas excepcionales, posibilitó un elevado dinamismo de la economía local, que se expandió a una tasa anual acumulativa de $5.2 \%$ entre 1870 y 1930, en tanto el producto per cápita lo hizo en $1.9 \%$ (Maddison, 2010) (véase gráfica 1).

Las tendencias globales empujaron al país a desempeñar ese papel en la división internacional del trabajo: las mejoras técnicas en la navegación permitieron el abaratamiento del transporte transoceánico que facilitó y potenció el comercio internacional, mediante el cual los países industrializados pugnaban por la colocación de los excedentes de su producción industrial y, a la vez, expandían la demanda de materias primas y alimentos. Por otro lado, en el marco de una creciente movilidad global del capital y del trabajo, la progresiva consolidación del gobierno central en la República Argentina en la segunda mitad del siglo xIx posibilitó la radicación masiva de inversión extranjera directa, la intensificación de flujos financieros y el inicio del periodo inmigratorio más relevante de su historia (Rocchi, 2000).

El desarrollo económico de Argentina durante esta etapa estuvo estrechamente asociado a los flujos de capital del exterior y a la expansión del comercio ultramarino, en particular con Gran Bretaña. Esta asociación se articuló a través de diferentes vías: por un lado, por la necesidad de colocar la producción primaria en los mercados internacionales, por otro, por los requerimientos de volúmenes crecientes de importaciones, tanto de bienes de capital como de consumo, en el marco de una economía en expansión. A la vez, se requería de un flujo creciente de inversiones, tanto directas como financieras, orientadas al desarrollo de la infraestructura para la exportación (sistema ferroviario y puertos), de los servicios públicos y de una incipiente producción industrial.

El crecimiento de la economía argentina durante este periodo no se circunscribió sólo al complejo agroexportador, sino que se asistió también a un incipiente desarrollo de la industria local, producto de los bajos costos de algunos insumos, los elevados costos de flete y la prevalencia du- 
rante algunos periodos de impuestos a la importación de productos. ${ }_{1}^{1}$ Sin embargo, el tejido manufacturero que se consolidó durante esta etapa, asociado al complejo agroexportador y a la provisión de un mercado doméstico en expansión, no alcanzó, por lo general, competitividad en el ámbito internacional.

Se debe señalar que el crecimiento de la economía argentina a lo largo de esta etapa no fue homogéneo. Es más, puede identificarse a la primera guerra mundial como un punto de inflexión, tras el cual se recuperaría la senda del crecimiento, aunque a tasas algo inferiores.

En la primera etapa, comprendida entre 1870 y el inicio de la primera guerra mundial, la economía argentina tuvo un crecimiento vertiginoso producto de su consolidación como exportador de productos de origen agropecuario. En dicha etapa, la economía se expandió a una tasa anual acumulativa de $6 \%$, en tanto el producto per cápita lo hizo en $2.5 \%$. Si bien la inserción plena de Argentina en el comercio internacional se inició a mediados del siglo xix, a partir de la exportación de lana producida en la región pampeana, fue con el desarrollo de la producción bovina y agrícola cuando se consolidó definitivamente $22 \mathrm{El}$ crecimiento de dichas producciones fue de carácter extensivo y el aumento de la producción basado en la continua expansión de la frontera productiva tuvo un importante efecto multiplicador, ya que la puesta en producción de nuevas tierras estaba asociada con la realización de obras de infraestructura requeridas para la comercialización de la producción. En particular, entre 1885 y 1900 se construyeron casi $13000 \mathrm{~km}$ de nuevas vías férreas asociadas, por lo general, a la expansión de la frontera agraria. Dichas inversiones fueron impulsadas por el Estado nacional a fin de garantizar el incremento de las exportaciones y realizadas, por lo general, por capitales privados de origen externo.

En esta primera etapa, la economía argentina enfrentó diferentes crisis asociadas al sector externo, siendo la crisis de la deuda en 1890 la que tuvo mayor impacto (véase gráfica 1). En efecto, el elevado nivel de importaciones, junto con el peso que fue adquiriendo el endeudamiento externo, condujeron a un estrangulamiento en el balance de pagos. En 1889, en un escenario de caída de los precios de exportación, los pagos de intereses y amortizaciones llegaron a representar $66.1 \%$ de las exportaciones totales ${ }^{3}$ lo que dio inicio a una profunda crisis económica que perduró hasta 1891 e implicó una contracción del producto bruto interno de 11.8 por ciento.

Las crisis del balance de pagos durante este periodo estuvieron asociadas con el relativamente reducido ritmo de crecimiento de las exportaciones, las cuales alcanzarían un mayor dinamismo con posterioridad a la extensión del ferrocarril, elemento indispensable para transportar la producción hacia los puertos de exportación. Entre los años 1885 y 1888 el endeudamiento externo creció a una tasa anual acumulativa de $98.2 \%$, mientras que las exportaciones de trigo lo hicieron a una tasa de $59.2 \%$ y en el caso del maíz alcanzó 42.1 \% (Ford, 1969).

\footnotetext{
${ }^{1}$ En relación con los derechos de importación no fueron establecidos con fines de protección, sino de recaudación. De esta manera, la cantidad de mercancías gravadas resultó elevada, mientras que el nivel de protección efectiva no lo fue porque terminó gravando tanto el producto final como los insumos o productos intermedios necesarios para su fabricación (Cortés, 1963). Por su parte, Chiaramonte (1971) considera que la aplicación de impuestos a las importaciones fue relevante en la conformación del crecimiento del incipiente sector industrial.

${ }^{2}$ Desde 1880 la producción ovina comenzó a trasladarse progresivamente hacia la región patagónica, a la vez que se extendía la producción de cereales, oleaginosas y bovinos en la región pampeana. Mientras que en 1881 las exportaciones de lana daban cuenta de prácticamente la totalidad de las ventas externas, en 1895 habían sido superadas en importancia por los cereales (Rocchi, 2000). El volumen total de exportaciones creció 16 veces entre 1870 y 1929 , mientras que en términos per cápita lo hizo 2.5 veces (Bértola y Ocampo, 2010).

${ }^{3}$ Según datos sobre cuentas externas tomados de Williams (1920).
} 
GRÁFICA 1. EVOLUCIÓN DEL PIB, EL PIB PER CÁPITA Y EL SALARIO REAL PROMEDIO EN ARGENTINA, 1870-1930 (EN NÚMERO ÍNDICE BASE $1900=100$ )

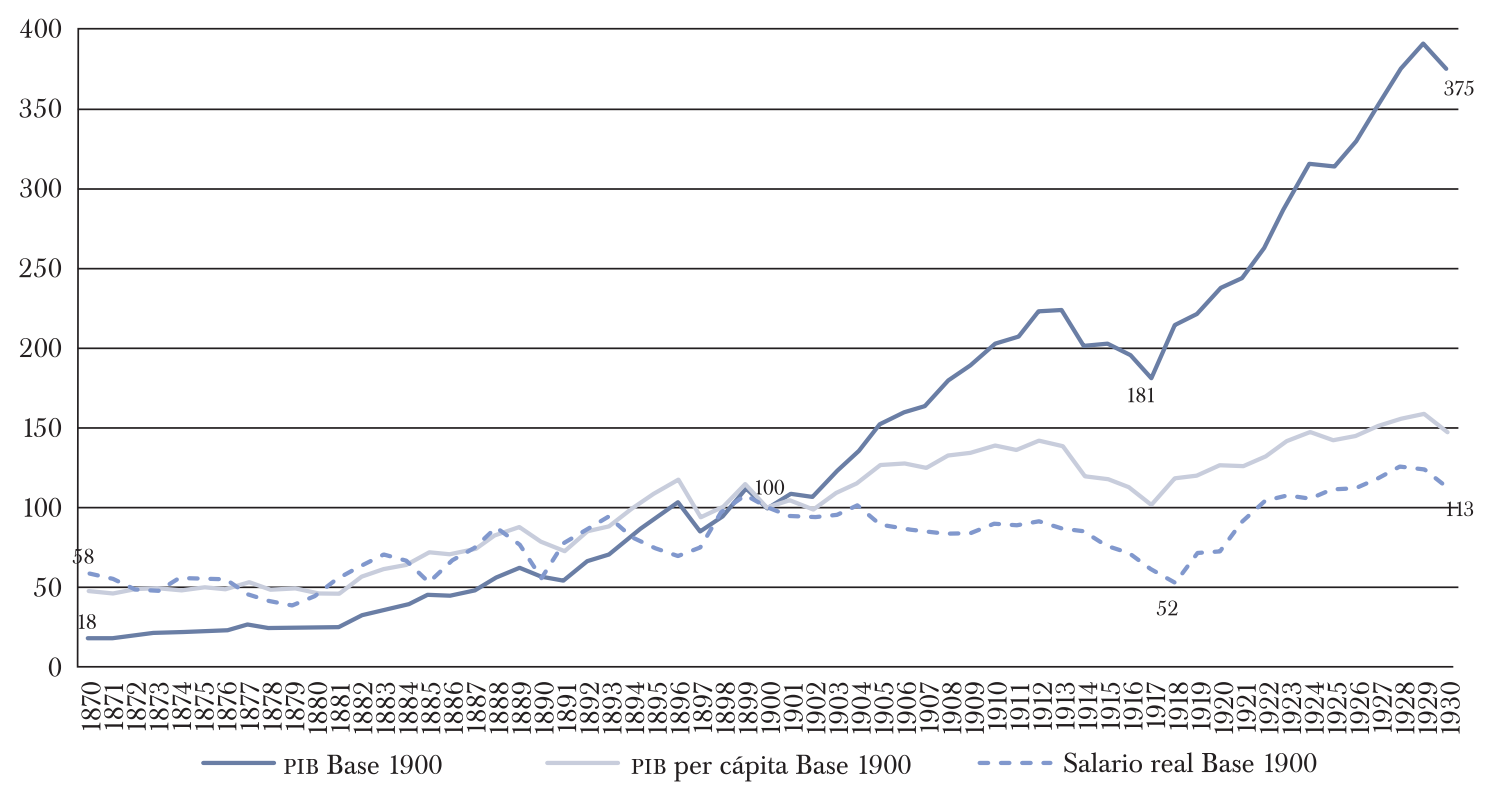

Fuente: elaboración propia con base en Maddison (2010) y Ferreres (2010).

Este desfase entre la tasa de crecimiento de las exportaciones y la necesidad de desarrollar la infraestructura requerida por el complejo agroexportador basado en el endeudamiento externo implicó estrangulamientos periódicos en la balanza de pagos. Así, el pago de intereses estaba constantemente supeditado al otorgamiento de nuevos préstamos, la expansión de las exportaciones y el nivel de los precios internacionales de los productos agropecuarios (Ford, 1969). A la vez, el crecimiento de la economía traía aparejadas mayores importaciones que presionaban aún más sobre el sector externo. Una vez iniciada la recuperación tras la crisis de 1890, el resultado comercial fue positivo en toda la década con excepción del año 1897, ante el resultado puntual de una mala cosecha. A la vez, el potencial conflicto bélico con Chile condujo a un incremento del déficit fiscal y dificultó el acceso a financiamiento externo, conduciendo a una desaceleración y leve contracción de la economía 4 Con el nuevo siglo, la economía retomó un camino de crecimiento que no se interrumpiría hasta la primera guerra mundial, expandiéndose a una tasa anual acumulativa de $6.4 \%$ entre 1900 y 1913. En un contexto de incremento en el valor de las exportaciones, como consecuencia de la mejora de los precios internacionales y el aumento en las cantidades exportadas, fue posible eliminar la restricción externa que había caracterizado a la economía argentina en las décadas previas (Cortés, 1998).

La primera guerra mundial marcó un punto de inflexión en la evolución de la economía local: la reversión de los flujos de capital, la caída de las exportaciones agropecuarias y la contracción de las importaciones condujeron a una prolongada contracción en el nivel de actividad, que disminuyó

\footnotetext{
${ }^{4}$ Williams (1920) indica que una plaga destruyó tres cuartos de la cosecha en ese año. A su vez, a causa de disputas limítrofes con Chile, ambos países estuvieron cerca de involucrarse en conflictos armados en 1895 y en 1898 . Si bien el conflicto finalmente no escaló, esta amenaza implicó un aumento del gasto armamentístico.
} 
a una tasa anual acumulativa de $1 \%$ entre 1913 y 1918. Una vez finalizado el conflicto bélico, la economía argentina recuperó la senda del crecimiento y se expandió a una tasa anual acumulativa de $4.9 \%$, en tanto que el producto per cápita, a $1.9 \%$. La desaceleración del crecimiento económico en los países europeos, y en particular Gran Bretaña, impactó en el ritmo de crecimiento del comercio internacional de productos agropecuarios en una primera instancia y, posteriormente, en una reducción en los precios internacionales. Estos factores, junto con la estabilización de la frontera agraria en Argentina, determinaron una tasa de expansión de la economía más reducida que en la etapa previa. Hasta la crisis de 1930 Argentina modificó su patrón de crecimiento hacia un modelo de industrialización por sustitución de importaciones que perduraría hasta mediados de la década de 1970.

El vertiginoso crecimiento que experimentó la economía argentina durante el modelo agroexportador fue acompañado por una sensible expansión en la demanda de mano de obra, la cual fue abastecida por un flujo migratorio sostenido a lo largo de este periodo. Como se verá, los flujos migratorios mundiales verificados durante ese periodo tuvieron un impacto muy significativo en el incipiente mercado de trabajo doméstico. En el caso argentino, la población migrante no sólo permitió abastecer una demanda de mano de obra en expansión, sino también contener los niveles salariales domésticos, en el contexto de un elevado crecimiento de la economía.

\section{LA ERA DE LAS MIGRACIONES MASIVAS}

Los flujos migratorios que tuvieron lugar entre los países europeos y el llamado Nuevo Mundo entre fines del siglo XIX y principios del siglo xx fueron de tal magnitud que empequeñecen las corrientes migratorias que ocurrieron con posterioridad, incluso las del presente. De acuerdo con distintos autores, entre 46000000 y $55000000^{5}$ de personas migraron transoceánicamente entre 1821 y 1915, y los flujos entre Europa y el Nuevo Mundo dieron cuenta de la mayor parte de estos movimientos (Caruana, 2015; Hatton y Williamson, 1998) ${ }^{6}$ Las migraciones se concentraron especialmente en el medio siglo anterior a la primera guerra mundial. Si bien más de $60 \%$ de los emigrantes tuvo a Estados Unidos como destino, existieron también importantes flujos de personas que arribaron a Canadá, Australia, Nueva Zelanda y diversos países de América Latina. En esta última región, Argentina y Brasil concentraron casi 80 \% de los arribos (Ashworth, 1977; Caruana, 2015; Hatton y Williamson, 1998; Lattes, 1985).

Inicialmente, la mayoría de los migrantes eran originarios del noroeste de Europa, especialmente Gran Bretaña (los emigrantes de las islas británicas, incluida Irlanda, representaron más de $40 \%$ de los migrantes totales) y la región de Escandinavia. En cambio, desde finales del siglo xix la mayor parte de los migrantes procedieron del sur de Europa (Italia, Portugal y España) y de Europa del Este (Austria-Hungría y Polonia).7 En este último periodo, las migraciones pueden vincularse centralmente con la crisis agropecuaria que afectó a la inmensa mayoría de los países de la periferia europea desde comienzos de la década de 1870.

\footnotetext{
${ }^{5}$ Las estadísticas sobre migraciones para ese periodo adolecen de varias dificultades que explican esas diferencias. Hatton y Williamson (1998) estiman 55000000 de migrantes, Caruana (2015) toma como referencia 46000000 , mientras que Ashworth (1977) considera 62000000 entre 1820 y 1930.

${ }^{6}$ Sólo las migraciones (forzadas) transoceánicas de esclavos desde África hacia América habían tenido con anterioridad una magnitud comparable (Hatton y Williamson, 1998).

${ }^{7}$ Así como Estados Unidos tuvo un papel preponderante como receptor de inmigrantes, no existió un único país que ocupara un lugar dominante en la emigración (Ashworth, 1977).
} 
Dicha crisis estuvo asociada a las sensibles transformaciones que enfrentó el sector agrícola europeo ante el abaratamiento de los costos de transporte y el ingreso al mercado mundial de nuevos países productores de materias primas de origen agropecuario como Estados Unidos, Canadá, Australia y Argentina. Estos últimos países, al contar con tierras de muy elevada fertilidad, lograron producir con costos relativos significativamente menores, lo que provocó un abrupto descenso en los precios internacionales: en 1894 el precio del trigo era poco más de un tercio del vigente en 1867. De esta forma, la caída de los precios internacionales y la mayor competencia externa determinaron una aguda crisis en la producción agropecuaria europea, la cual todavía empleaba entre 40 y 50 \% de los trabajadores varones en los países industriales -con excepción de Reino Unidoy hasta $90 \%$ en los demás países (Hobsbawm, 1998).

Ante esta crisis agrícola, "las dos respuestas más habituales entre la población fueron la emigración masiva y la cooperación, la primera protagonizada por aquellos que carecían de tierras o tenían tierras pobres y la segunda fundamentalmente por los campesinos con explotaciones potencialmente viables" (Hobsbawm, 1998, p. 44). Así como la disminución de los costos de transporte había revolucionado al sector agrícola, también los factores tecnológicos influyeron positivamente sobre las posibilidades de migración, al permitir desde la segunda mitad del siglo XIx una navegación regular, segura, relativamente corta - tres semanas- y barata en los buques de vapor (Ashworth, 1977; Cortés, 1979) ${ }^{8}$ La disminución en los costos de transporte transoceánico fue una condición de posibilidad para las grandes oleadas migratorias registradas en ese periodo.

Asimismo, las políticas favorables a la inmigración (europea) en los países del Nuevo Mundo potenciaron los flujos migratorios. En diversos países, incluyendo Argentina, se crearon agencias de inmigración cuya tarea era atraer y facilitar la incorporación de población, a fin de incrementar la mano de obra disponible en el marco de economías en franca expansión. Sin embargo, estas políticas se volvieron gradualmente más restrictivas en las décadas de 1910 y 1920 cuando no sólo se limitó el número total de ingresos, sino que además se ejerció una discriminación hacia los inmigrantes según país de origen. No sucedió lo mismo en Argentina que siguió siendo un país prácticamente de libre entrada para la inmigración (Ashworth, 1977; Solimano, 2004).

Si bien los efectos de la crisis agraria se sintieron en los países europeos, especialmente en las décadas de 1870 y 1880, las migraciones masivas continuaron y fueron incluso más intensas en las primeras décadas del siglo xx, cuando el crecimiento de la producción industrial y el empleo en ese sector había ido compensando los efectos de la disminución de los ingresos agrícolas (Cortés, 1979). La persistencia de un diferencial salarial significativo entre los países del Viejo y el Nuevo Mundo habría sido un estímulo para dichas migraciones, sumado a los efectos de la migración en cadena. Es decir, la existencia de grupos de emigrados, como parientes y amigos, que apoyaban moral y económicamente las nuevas migraciones y brindaban información -positiva- sobre el nuevo destino (Hatton y Williamson, 1998).

La migración a Argentina, si bien fue moderada en términos de su participación en los flujos migratorios globales, fue muy relevante en términos de su incidencia sobre la estructura demográfica local, habida cuenta de la reducida población que presentaba el país en las últimas décadas del siglo xix. Entre 1870 y 1930 el número de inmigrantes que arribó a las costas de Argentina

\footnotetext{
${ }^{8}$ Hasta bien entrado el siglo XIX el costo del transporte interoceánico había resultado demasiado elevado para los trabajadores libres. Sólo se solventaba cuando dicho costo se pagaba con servidumbre, o en el caso de los esclavos y de los convictos trasladados (Hatton y Williamson, 1998).
} 
alcanzó casi 100000009 mientras que la inmigración neta (restando las emigraciones) fue superior a 4000000 de personas, sobre un nivel de población que era de algo más de 1800000 en 1870. Estas voluminosas inmigraciones desde ultramar determinaron que la tasa de crecimiento poblacional entre 1870 y 1930 fuese equivalente a $3.2 \%$ anual acumulativo ${ }^{10}$ Se trata de un valor muy superior, no sólo a la tasa de los viejos países europeos, sino también a la verificada en América Latina y en los países en rápida expansión económica en ese periodo como Australia, Canadá, Estados Unidos y Nueva Zelanda (véase gráfica 2). Entre 1870 y 1930 la población argentina se expandió más que la de cualquier otro país occidental.11

La distancia entre la tasa de crecimiento poblacional de Argentina y la de los otros grandes destinos de migrantes transoceánicos de ese periodo (Estados Unidos, Australia y Canadá, principalmente) es especialmente importante desde 1890 y hasta la década de 1920. Por otro lado, si bien la proporción de inmigrantes sobre la población se ve afectada por la relativamente baja población que existía en Argentina al inicio del periodo, la magnitud del crecimiento poblacional es también muy relevante en términos absolutos.

Así, mientras que en 1870 las poblaciones de Argentina y de Australia eran prácticamente idénticas -alrededor de 1800000 de habitantes-, en 1930 Argentina contaba con 12000000 de habitantes, superando en 5400000 a Australia, a la cual casi duplicaba en población. Respecto de Canadá, en 1870 Argentina tenía la mitad de población y para 1930 la superaba en 1400000 de personas. Finalmente, la comparación con Estados Unidos muestra mayores diferencias de escala, ya en 1870 ese país contaba con una población de 40000000 de personas y en 1930 ascendía a 123400 000. Más allá de tener una población significativamente más reducida, Argentina se expandió en términos relativos bastante más rápido que aquel país. Mientras que en 1870 la población argentina representaba $4.5 \%$ de la estadunidense, dicha proporción se había elevado hasta casi $10 \%$ en 1930 .

El menor tamaño inicial de la población argentina, así como la magnitud de las corrientes migratorias determinó que la proporción de inmigrantes durante el modelo agroexportador fuese particularmente elevada. Según se explica en Recchini de Lattes y Lattes (1975), Argentina en este periodo fue el país que tuvo la mayor proporción de migrantes europeos sobre la población total. En Argentina, de acuerdo con el censo de 1914, $65 \%$ de los pobladores eran inmigrantes

\footnotetext{
${ }^{9}$ Estas cifras que surgen de estadísticas oficiales de Argentina no resultan compatibles con otras estadísticas que recopilan movimientos de emigrados según país de destino, y que exhiben un número menor de arribados a Argentina. Las diferencias parcialmente se originan en el hecho de que las estadísticas sobre migraciones para el periodo son imperfectas (se basan en registros de pasajeros arribados y salidos del puerto de Buenos Aires en segunda y tercera clase, por vía directa desde Europa o indirecta desde otra ciudad portuaria). Por ello, diversos autores (Recchini de Lattes y Lattes, 1975; Vázquez, 1971) han realizado ajustes posteriores en las mismas. Con el fin de mantener la consistencia interna de la información, para el cálculo de la proporción de migraciones a Argentina respecto del total mundial se utilizaron las cifras de Ashworth (1977).

${ }^{10}$ Debe resaltarse que los migrantes contribuyeron al crecimiento poblacional, tanto en forma directa, como indirecta, a través del propio crecimiento vegetativo. Según Recchini de Lattes y Lattes (1975) la contribución de la migración al crecimiento poblacional se incrementa a casi $100 \%$ cuando se tiene en cuenta el componente indirecto.

${ }^{11}$ Las proyecciones de población se basan en los censos nacionales de población para los años en que estos se realizaron. En los operativos censales de 1869 y 1895 se censó sólo a la población de territorios bajo control del Estado, excluyendo al Chaco y la Patagonia. En el censo de 1914, en cambio, estas regiones ya estaban incorporadas al territorio nacional y por lo tanto fueron incluidas (Otero, 2006). Se considera que la población que podía conformar la oferta laboral era aquella que fue efectivamente censada y que habitaba territorios bajo control del Estado.
} 


\section{GRÁFICA 2. TASA ANUAL ACUMULATIVA DE CREGIMIENTO POBLACIONAL EN PAÍSES Y REGIONES SELECGIONADAS, 1870 Y 1930 (EN PORGENTAJES)}

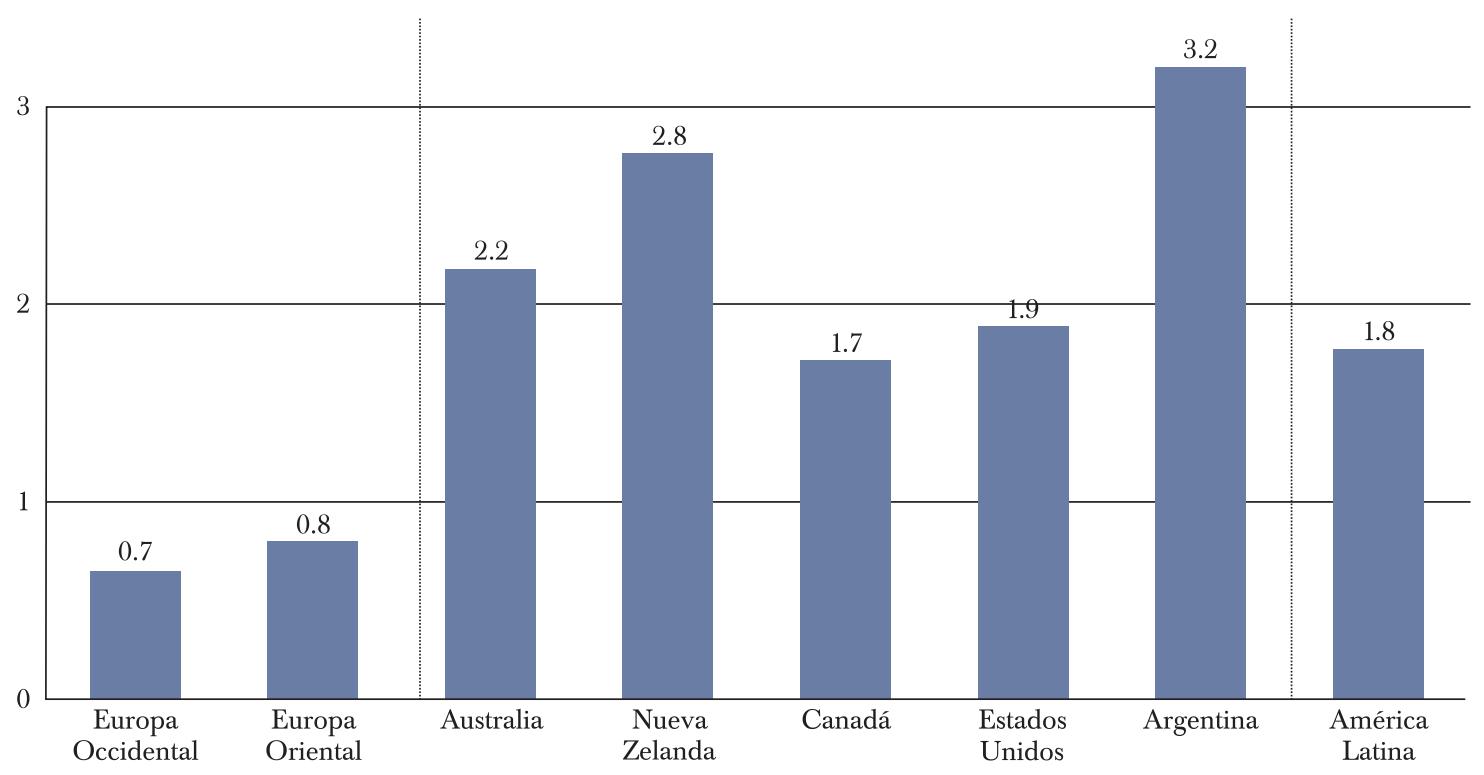

Fuente: elaboración propia con base en Maddison (2010).

(30\%) o hijos de inmigrantes (35\%). Mientras que en Estados Unidos en 1910 menos de $16 \%$ eran inmigrantes y la proporción de población nativa que tenía al menos un progenitor extranjero era de 38 \% (Landry, 1949 citado en Torrado, 2003).

Esta fuerte afluencia de inmigrantes y la elevada tasa de crecimiento poblacional distinguen a Argentina en este periodo. De todos modos, las migraciones siguieron a grandes rasgos los ciclos de las migraciones transoceánicas, que implicaron una reducción relativa tras la crisis mundial de $1890 \mathrm{y}$, sobre todo, un fuerte descenso en los años de la primera guerra mundial (véase gráfica 3).

La cifra de arribos hacia Argentina comenzó una tendencia claramente creciente desde 1880, hasta alcanzar un máximo de 260000 inmigrantes en el año 1889. Durante ese primer periodo, el índice de radicación de estos migrantes fue muy elevado: los emigrados fueron en promedio sólo $18 \%$ de los inmigrantes entre 1881 y 1889 . Durante la década siguiente, las entradas de inmigrantes fueron en promedio similares, aunque con un nivel de retención significativamente menor, que implicó que los emigrados alcanzasen 57 \% de los entrantes. La crisis económica a fines del siglo XIX tuvo su efecto sobre las entradas y salidas de extranjeros, tal como había sucedido en 1890, aunque con menor intensidad. Una vez superada esta crisis, se inició el periodo de mayor afluencia de inmigrantes hasta entonces, con un promedio de casi 250000 por año entre $1901 \mathrm{y}$ 1913. Precisamente en los dos últimos años antes del estallido de la primera guerra, se alcanzó un máximo de 370000 ingresos de inmigrantes de ultramar. Sin embargo, la tasa de radicación se mantuvo en los niveles relativamente bajos que había tenido desde la década de 1890, siendo los emigrantes prácticamente la mitad de los llegados a Argentina. 


\section{GRÁFICA 3. SALDOS MIGRATORIOS Y PROPORGIÓN ENTRE EMIGRACIÓN E INMIGRACIÓN, 1870-1930 (EN MILES DE PERSONAS Y PORCENTAJES)}

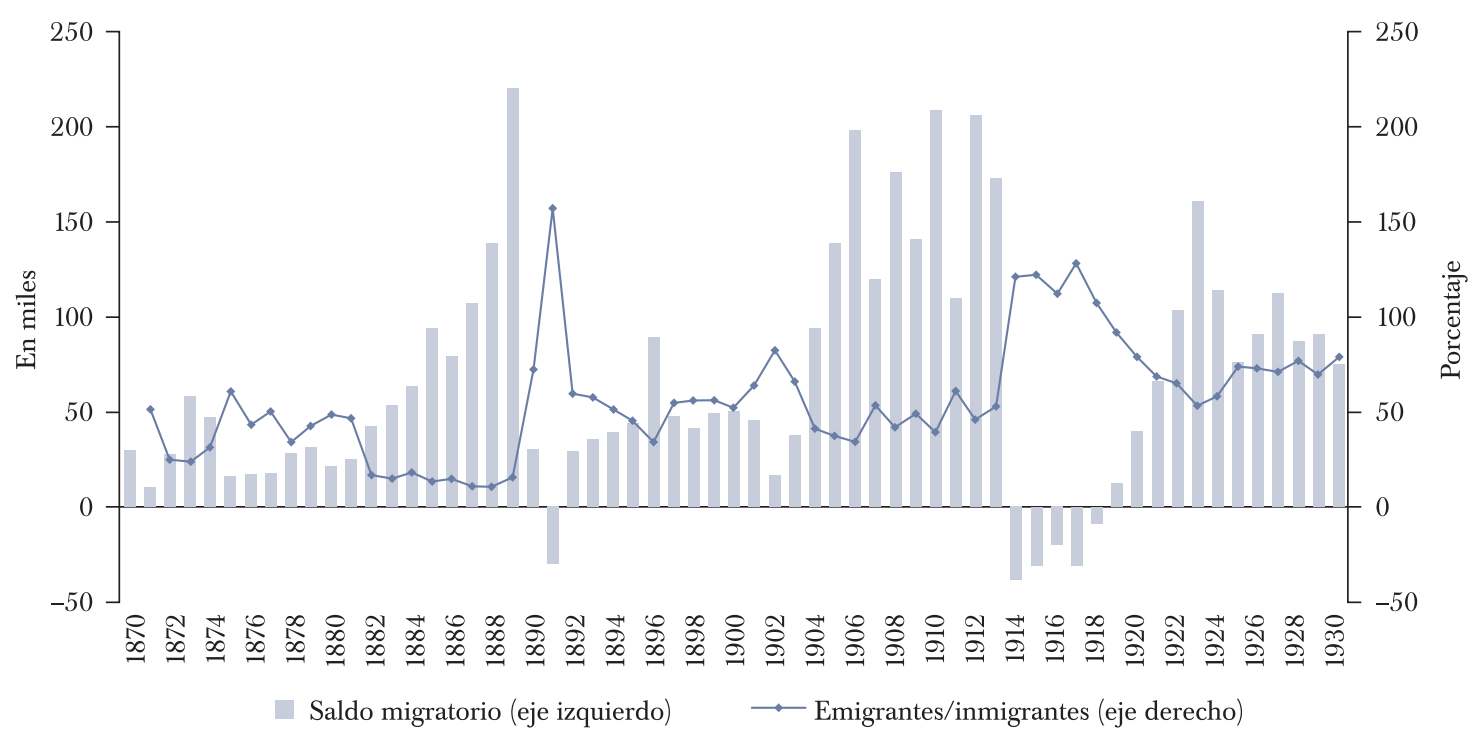

Fuente: elaboración propia con base en Vázquez (1971).

Durante la primera guerra mundial se observó una importante interrupción en los flujos de salida de población desde Europa, que implicó que entre 1915 y 1919 los emigrantes se redujeran $77.4 \%$ respecto de años los inmediatamente anteriores (1911-1914) (Willcox, 1929). A su vez, la economía argentina fue severamente afectada por el conflicto bélico mundial de modo que mientras los inmigrantes arribados se reducían a la mitad, la emigración promedió anualmente 162000 personas. En términos netos, 116000 extranjeros dejaron el país en esos años 12

Finalmente, con la recuperación económica que siguió a la finalización de la primera guerra mundial retornó el ingreso masivo de europeos, que promediaron anualmente casi 320000 personas durante la década de 1920, decenio durante el cual se verificó un ritmo de entradas mayor que cualquiera de las anteriores. Sin embargo, el ritmo de salidas del país fue aún más intenso que en los años previos a 1914: los emigrados representaron $69 \%$ de los que ingresaron al país. Esta alta proporción de inmigrantes que no se estableció en el país, sino que volvió a emigrar, que con distinta intensidad se mantuvo durante todo el periodo, se destaca como una característica que

\footnotetext{
${ }^{12}$ La mayor dificultad y peligrosidad del viaje transatlántico, así como ciertas restricciones para la emigración de potenciales combatientes, influyeron negativamente sobre las salidas desde Europa. La emigración hacia Argentina, a su vez, resultó desincentivada por la recesión y caída de ingresos reales en este país. En relación con los retornos, se los asocia principalmente con la situación crítica de la economía argentina. Si bien existió un número de extranjeros que regresó a su país de origen durante la guerra con el fin de alistarse como combatiente, se trata de una proporción menor en el conjunto de emigrados. En Tato (2011) se muestra que 32430 miembros de la comunidad italiana, la de mayor presencia en Argentina, se embarcaron como reservistas tras la convocatoria de su país de origen en 1915. Sólo en ese mismo año la salida total de emigrantes fue de 168 600. Gran parte de los que retornaron eran españoles, país que fue neutral ante la guerra (Otero, 2012).
} 
distingue a Argentina respecto de otros destinos de migración. Al respecto, Recchini de Lattes y Lattes (1975) afirman que Argentina tuvo la menor tasa de retención de migrantes, medida como porcentaje de salidas sobre las entradas, respecto del resto de países receptores.

Más allá de las oscilaciones, el ingreso de migrantes a Argentina fue creciendo en importancia relativa respecto de otros países de destino. Mientras en la década de 1870 representaron $7 \%$ del total de las migraciones transoceánicas, desde la década siguiente superaron $10 \%$, alcanzando en la primera década del siglo xx casi $13 \%$ (Ashworth, 1977). En este punto, Argentina incrementó su importancia relativa como destino para los inmigrantes, en parte como consecuencia de las crecientes trabas a la inmigración que se establecieron en otros países receptores.

\section{Diferentes políticas migratorias en los principales países receptores}

Un breve resumen de las políticas hacia la inmigración aplicadas en otros países permite ver el caso argentino en perspectiva. Tal como se mencionó, Estados Unidos fue durante todo este periodo el principal destino para los migrantes transoceánicos. Sin embargo, la aprobación de la Percentum Limit Act o Quota Act de 1921, en el contexto de una recesión económica, implicó un importante punto de inflexión en la política de inmigración de este país, restringiendo severamente las entradas 13 La regulación implicó limitar numéricamente la inmigración mediante sistemas de cuotas, que implicaban admitir en mayor medida inmigrantes llegados de Europa del norte y del oeste (Reino Unido y Alemania principalmente), frente a los provenientes de Europa del sur y del este (como Italia y Polonia). ${ }^{14}$ Así, el país que había atraído casi $60 \%$ de los emigrantes europeos en 1901-1910, redujo esa proporción a 42.6 \% en 1921-1924, sobre una población migrante que, a su vez, representaba sólo alrededor de un tercio de la de aquel periodo (Willcox, 1929). Una nueva regulación en 1924 resultó aún más restrictiva en cuanto a los cupos admitidos.

En Canadá, donde desde 1896 se verificó un creciente flujo de inmigrantes desde Estados Unidos y ultramar, comenzaron a adoptarse, prácticamente desde ese mismo momento, medidas que regulaban y orientaban la inmigración. El sistema migratorio que se conformó basaba los incentivos y restricciones en el país de origen del migrante. El objetivo declarado de la política era atraer a agricultores y trabajadores desde Gran Bretaña, Estados Unidos y el noroeste de Europa para que se asentaran en el oeste del país, aunque ante el exceso de demanda de mano de obra se reclutó también a inmigrantes de Europa central y oriental. Tras la primera guerra mundial se produjeron modificaciones importantes en esta política, que supusieron expandir la regulación gubernamental sobre el nivel, la temporalidad de ingreso y la composición étnica de la inmigración. El primer cambio importante, en 1919, consistió en establecer una prueba de alfabetización para todos los posibles inmigrantes, así como permitir que el gobierno limitase discrecionalmente el número de ingresos. La política de Canadá hacia la inmigración implicó, en general, adaptar los flujos de entrada a la capacidad de absorción de la economía y el mercado laboral, de modo que se restringieron las entradas en épocas de crisis económica y se relajaron los criterios de admisión durante los periodos de mayor demanda de mano de obra (Green y Green, 1999, 2004).

\footnotetext{
${ }^{13}$ Algunas restricciones previas se habían implementado en 1917 a través de la no admisión de inmigrantes analfabetos (Husband, 1922).

${ }^{14} \mathrm{El}$ acta de 1921 restringió anualmente el número de inmigrantes admitidos desde cualquier país al $3 \%$ sobre el número de residentes de ese mismo país que viviesen en Estados Unidos en 1910. No existían límites a la inmigración desde países de América Latina y no se admitía la inmigración desde países asiáticos identificados en leyes de inmigración ya vigentes. La aplicación de esta fórmula implicó una importante merma en el número de inmigrantes con posterioridad a 1921 (Husband, 1922; Willcox, 1929).
} 
Por su parte, en Australia las políticas de atracción y limitación de la inmigración resultaron relevantes y variables en el tiempo. Debe considerarse que, sobre todo en función de la distancia y el costo de transporte, Estados Unidos y Canadá constituían un destino mucho más atractivo para los emigrantes del Reino Unido que Australia. De allí que los subsidios otorgados por el Estado australiano para el traslado y establecimiento de migrantes tuviesen una importancia mayor que para otros destinos. A lo largo del tiempo, tanto el tamaño como la naturaleza de los programas de asistencia se modificaron en función de la situación del mercado de trabajo: variaba tanto la magnitud del fondo anual y el nivel de subsidio a los pasajes como la atracción de determinadas clases de migrantes, a través de tarifas de transporte diferenciales (Kelley, 1965). El partido laborista, que llegó al poder en 1901, restringió duramente el ingreso de inmigrantes asiáticos (política de tinte racista conocida como White Australia) y adoptó una postura más cauta en cuanto a alentar las llegadas netas de ultramar a través de políticas estatales.

Estas políticas marcan una clara diferenciación con las llevadas adelante por el Estado argentino, sobre todo tras la finalización de la primera guerra mundial, que continuó con una política de fronteras abiertas para la inmigración, en un contexto en donde comenzaba a evidenciarse la existencia de excedentes de mano de obra en el mercado de trabajo local. Mientras otros países imponían diversos tipos de restricciones, Argentina siguió siendo un país de libre entrada para la inmigración, lo que implicó que recibiera parte de los contingentes que no podían ingresar en otros países, especialmente Estados Unidos. El incremento relativo de población arribada desde Europa central fue una consecuencia de este desvío de población migrante (Ashworth, 1977; Devoto, 2004; Sánchez-Alonso, 2004; Solimano, 2004) 15

En Argentina, existió en todo el periodo del modelo agroexportador amplia libertad migratoria. La Constitución de 1853, como marco general, alentaba la inmigración y equiparaba los derechos civiles entre nativos y extranjeros residentes en el país. La Ley de Inmigración, sancionada en 1876 y que estaría vigente por un siglo, señalaba sólo dos motivos de restricción para la admisión de inmigrantes: la salud y la edad (menores de 60 años) ${ }^{16}$ La aplicación de la legislación fue, además, bastante laxa. Los inmigrantes, que se definían como aquellos que llegaban de ultramar (no de otros destinos) en segunda o tercera clase, recibían algunos beneficios, como alojamiento gratuito a su llegada al país y traslado a costa del Estado al punto donde fueran a fijar su domicilio. Sólo en un corto periodo (1887-1889) se subsidió el pasaje trasatlántico. Más allá del marco normativo favorable, existió durante el siglo XIX una política activa para atraer inmigrantes europeos a través de agentes de inmigración. De todos modos, las cadenas migratorias fueron el principal mecanismo de información y promoción de la inmigración (Devoto, 2004; Novick, 1989).

La inmigración no sólo tuvo un impacto significativo sobre las condiciones imperantes en el mercado de trabajo, tal como se analiza en la próxima sección, sino también un severo impacto demográfico. Un ejemplo contrafáctico es útil para dar cuenta de la magnitud del crecimiento poblacional que tuvo Argentina entre 1870 y 1930. Si en ese periodo el país hubiese registrado un

\footnotetext{
${ }^{15}$ No sólo Argentina sino en general América Latina, dentro la cual Argentina era el principal destino migratorio, fue "una de las pocas regiones del Nuevo Mundo que continuaba abierta a la inmigración de masas después de 1914" (Sánchez-Alonso, 2004, p. 155). En Brasil, puesto que los salarios relativos no resultaban tan atractivos, la inmigración se fomentó mediante una selectiva política de pasajes subsidiados, que perduró hasta 1927.

${ }^{16}$ En 1902 la Ley de Residencia permitió la expulsión de inmigrantes "cuya conducta comprometa la seguridad nacional o perturbe el orden público”. La aplicación de esta ley, centrada en líderes sindicales anarquistas y socialistas, fue limitada en términos cuantitativos.
} 
crecimiento poblacional similar al promedio de Australia y Canadá, en 1930 hubiera tenido una población inferior a los 4000000 de habitantes. El mismo resultado se hubiera obtenido a partir de crecer a la misma tasa que Estados Unidos. Es decir, menos de un tercio de la población que alcanzó efectivamente Argentina en 1930.

\section{LA EVOLUCIÓN DEL MERCADO DE TRABAJO}

La lógica de funcionamiento del mercado de trabajo durante el modelo agroexportador estuvo estrechamente relacionada con los flujos de inmigrantes que -en términos netos- totalizaron más de 4000000 de personas entre los años 1870 y 1930. Tal como se analizó, la magnitud del flujo inmigratorio fue, en términos relativos, muy superior a la de otros países occidentales de rápido crecimiento poblacional con los que se suele comparar a Argentina: Australia, Canadá y Estados Unidos.

Las corrientes migratorias hacia Argentina se explican por el elevado crecimiento económico que experimentó el país en aquellos años, proceso que se tradujo en un aumento extraordinario de la demanda de mano de obra. El incremento en la demanda de trabajadores no estuvo asociado solamente a la expansión del sector agropecuario, sino también al desarrollo de la construcción y los servicios asociados a la exportación de productos primarios (Arceo, 2003). A la vez, aumentó la producción de bienes y servicios destinados al abastecimiento del creciente mercado interno (Beccaria, 2006).

La demanda de mano de obra fue cubierta, en gran medida, con la población migrante. Para atraer esta población, se requirió el sostenimiento de un nivel salarial relativamente más elevado que el verificado en sus países de origen, lo cual era posible dada la elevada productividad del sector agropecuario pampeano.

Como se analizó anteriormente, si bien a lo largo del periodo se verificó una elevada tasa de crecimiento de la economía, la misma no estuvo exenta de fluctuaciones que afectaron la demanda laboral y, por ende, la corriente inmigratoria. Los periodos de retracción de la economía local fueron acompañados, por lo general, por una contracción o incluso una salida neta migrantes.

El desempleo y el subempleo fueron fenómenos acotados temporalmente y no de carácter estructural, ya que la emigración en los periodos de contracción económica conducía a una disminución en la oferta de trabajo (Beccaria 2006, Departamento Nacional del Trabajo, 1916). Sin embargo, tal como se analizará en la presente sección, se sostiene que la magnitud del flujo migratorio permitió contener el incremento de los salarios reales en un contexto de elevadas tasas de crecimiento de la economía.

A su vez, la práctica inexistencia de legislación protectora del trabajo y la inestabilidad estacional en la demanda de mano de obra por parte del sector agropecuario conducían a la conformación de un mercado laboral flexible en términos de los plazos de contratación y con sensibles oscilaciones en los niveles de empleo y en los salarios a lo largo del año (Beccaria, 2006).

Se verificaba, además, cierta complementariedad entre el trabajo urbano y el rural, de modo que los trabajadores que durante las cosechas se empleaban en el sector primario podían ocuparse durante el resto del año en los sectores urbanos, principalmente en la construcción ${ }^{17}$ Este com-

\footnotetext{
${ }^{17}$ El traslado implicaba dejar el trabajo en la ciudad y no tener certeza de contar con ocupación al regresar, de modo que esta población habría sufrido frecuentemente de desocupación y subocupación, especialmente en los periodos recesivos.
} 
portamiento recién comenzó a perder significación en los primeros años de la década de 1920, cuando el proceso de mecanización del sector agropecuario pampeano permitió una diminución en la demanda de mano de obra para las tareas de recolección (Pianetto, 1984).

La estacionalidad de la actividad rural, con su elevada demanda de mano de obra para los meses de cosecha, puede relacionarse también con los importantes flujos de salida de población migrante. En efecto, ante los elevados salarios relativos respecto de sus países de origen, numerosos migrantes provenientes de Europa emprendían el viaje transoceánico con el objetivo de emplearse en Argentina durante la cosecha y volver a su país de origen al finalizar la misma (Beccaria, 2006; Pianetto, 1984). De todos modos, el nivel inusitadamente bajo de las tasas de retención de inmigrantes en relación con los otros destinos principales conduce a la necesidad de pensar en causas adicionales, como se verá más adelante.

\section{El mercado de trabajo en las distintas etapas}

Si bien las características generales señaladas son comunes a la evolución del mercado de trabajo durante el modelo agroexportador, es posible identificar comportamientos diferentes entre los distintos subperiodos que lo componen. Los mismos no coinciden estrictamente con la periodicidad establecida en la primera sección del presente trabajo, ya que durante la fase de elevado crecimiento del modelo agroexportador (1870-1913) se verifican dos etapas disímiles en términos de la evolución del mercado laboral. Por esta razón, se evaluarán tres periodos. El primero de ellos abarca las tres últimas décadas del siglo XIx, la segunda etapa comprende desde inicios del siglo xx hasta la finalización de la primera guerra mundial y la última desde la culminación de dicho conflicto bélico hasta el abandono del modelo agroexportador a comienzos de la década de 1930.

A lo largo de las tres últimas décadas del siglo xIx, el flujo inmigratorio fue acompañado por el incremento de los salarios reales medios, que se expandieron a una tasa anual acumulativa de $1.8 \% \sqrt{18}$ Ello implicó que a comienzos del siglo xx las remuneraciones prácticamente duplicaran las existentes a comienzos de la década de 1870. Sin embargo, la inestabilidad económica a lo largo de la década de 1890 se tradujo en fuertes oscilaciones en la demanda de trabajo y en las remuneraciones de los trabajadores, así como en los saldos migratorios.

Si bien los salarios reales se expandieron a una tasa apreciable, lo hicieron por debajo del crecimiento medio de la economía y del producto bruto per cápita - proxy del producto por trabajadorque aumentó en este periodo a una tasa anual acumulativa de $2.5 \%$. Por lo tanto, puede afirmarse que las elevadas tasas de crecimiento beneficiaron centralmente a las distintas fracciones del capital, en tanto los asalariados perdieron participación en el valor agregado generado en la economía argentina 19

\footnotetext{
${ }^{18}$ Con base en información de Williamson (1995) que reconstruye series de salarios reales. Para el caso de Argentina utiliza salarios correspondientes a trabajadores urbanos de la ciudad de Buenos Aires. Se toma esta fuente debido a que este autor construyó - para el periodo bajo análisis- series comparables de salarios reales relativos para quince países (entre ellos los que resultan más relevantes para este estudio). Los salarios están expresados en una unidad de tiempo común (hora) y corresponden en todos los casos a trabajadores no calificados de áreas urbanas. A su vez, han sido ajustados por paridad de poder de compra (es decir, representan el poder adquisitivo de canastas de consumo similares en los diferentes países). Por su parte, para Argentina, Beccaria (2006) compara salarios referidos a los ámbitos rural y urbano y concluye que su evolución es similar, por tratarse de mercados de trabajo integrados.

${ }^{19}$ Lamentablemente no se dispone de una serie de información confiable a cerca de la cantidad de ocupados durante este periodo, lo cual impide una estimación de la evolución de la productividad media de la economía.
} 
El sostenimiento del flujo de migrantes demandaba la existencia de un nivel salarial más elevado que el verificado en los países de origen. A la vez, los salarios locales debían competir con los de otros países demandantes de mano de obra. En las tres últimas décadas del siglo xix, los salarios locales representaron en promedio 79 \% de los prevalecientes en Gran Bretaña, pero fueron notoriamente más elevados que los vigentes en los países expulsores de población. En particular entre 1870 y 1900 los salarios en España fueron 25 \% menores que los de Argentina, con una brecha que tendía a acrecentarse, mientras que los de Italia eran 52 \% más bajos. A la vez, en esos países se verificaba un elevado nivel de desocupación. Argentina poseía, en cambio, un nivel retributivo inferior al vigente en otros países receptores de población como Estados Unidos, Australia y Canadá (véase gráfica 4$) 20$

El elevado crecimiento de la economía argentina entre 1870 y 1900 respecto de los países anteriormente mencionados, junto con la sensible expansión de la demanda de mano de obra, permitió un incremento mayor de los salarios reales a lo largo del periodo. Así, a comienzos del siglo xx, los salarios en Argentina habían reducido su brecha respecto de los otros países de destino de las migraciones. Los salarios en Australia eran $32 \%$ superiores a los de Argentina y dicha proporción se elevaba a 48.1 \% en el caso de Canadá y a $47.1 \%$ respecto a Estados Unidos.

El inicio del siglo xx marca un punto de inflexión en la evolución del mercado de trabajo en Argentina, al menos en materia salarial, ya que en contraposición a lo acontecido en el periodo previo los salarios reales se redujeron en los años sucesivos aun en un contexto de elevado dinamismo económico (véase gráfica 1).21

En esta segunda etapa comprendida entre inicios del siglo xx y la finalización de la primera guerra mundial se verificó, primero, un proceso de largo estancamiento de la remuneración promedio de los trabajadores hasta 1912 y, luego, una importante contracción que implicó para 1918 una caída prácticamente a la mitad en términos de poder adquisitivo. Esta trayectoria salarial, en un periodo que en conjunto implicó un crecimiento económico significativo ${ }^{22}$ se tradujo en un sensible empeoramiento de la estructura distributiva y, por ende, en una menor participación del trabajo en el producto. Este proceso puede asociarse con la intensificación de los flujos migratorios desde comienzos del siglo xx, los cuales permitieron que el incremento de la oferta de mano de obra más que compensara la demanda y, de esta forma, se pudieran contener las demandas de los trabajadores en pos de incrementar sus remuneraciones.

La trayectoria de los salarios reales se tradujo en una elevación de la tasa de ganancia, tanto de las fracciones del capital agrario como industrial y de servicios. En efecto, en un contexto de elevadas tasas de crecimiento económico y de empleo, el incremento incesante de la oferta de mano de obra permitió aumentar la competencia entre los trabajadores en la esfera laboral y de esta forma reducir los salarios reales. Tal como se analizó en la sección anterior, durante la primera década del siglo xx y hasta el advenimiento de la primera guerra mundial se asistió a un crecimiento vertiginoso en el ingreso de migrantes, aunque las tasas de radicación se mantuvieron en niveles relativamente bajos. Esto último puede considerarse también un signo del hecho de que una parte importante de los recién llegados no podía acceder a ocupaciones e ingresos estables.

\footnotetext{
${ }^{20}$ La comparación en los salarios internacionales se realizó con base en información de Williamson (1995), que considera salarios reales ajustados por paridad de poder adquisitivo para trabajadores no calificados de diferentes países.

${ }^{21} \mathrm{El}$ índice de salarios de los trabajadores industriales elaborado por Ferreres (2010) indica también un estancamiento de los mismos a lo largo de las dos primeras décadas del siglo xx.

${ }^{22}$ Entre 1900 y 1918 la economía argentina creció a una tasa anual acumulativa de 4.3 por ciento.
} 


\section{GRÁFICA 4. DIFERENCIA DE SALARIO REAL EN PAÍSES SELECGIONADOS RESPECTO DE ARGENTINA, 1870-1930 (EN PORGENTAJE SOBRE SALARIO DE ARGENTINA)}

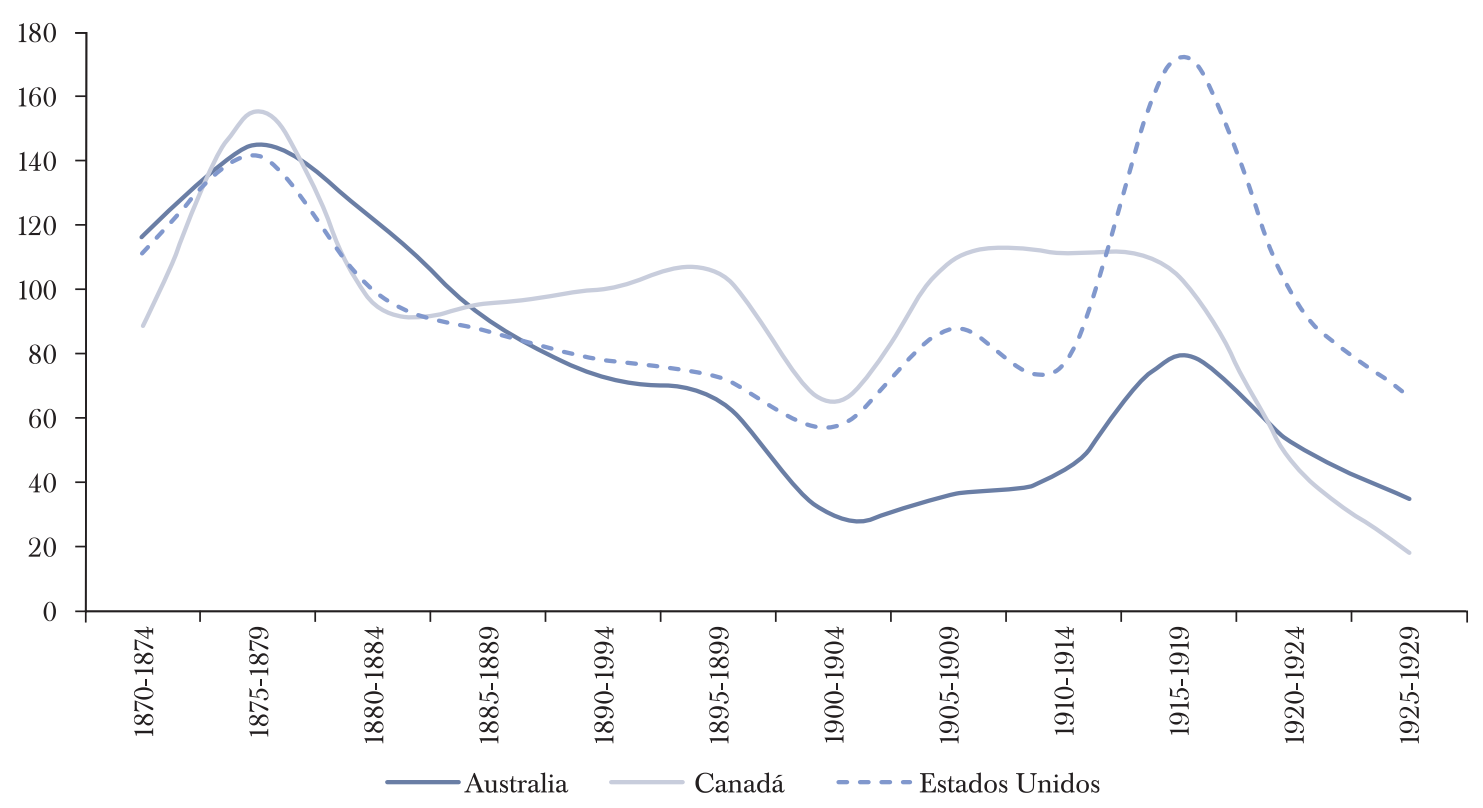

Fuente: elaboración propia con base en información de Williamson (1995).

Si bien el deterioro del salario real en Argentina disminuyó el atractivo para la inmigración respecto a otros países demandantes de mano de obra, se mantenía todavía un nivel salarial relativamente elevado respecto de los países expulsores de población. A su vez, se observa también un aumento en las restricciones para la migración a otros destinos, como se explicó en la tercera sección de este artículo. Dichas restricciones obedecían, por lo general, a las presiones internas de las organizaciones gremiales y políticas de trabajadores, tendentes a moderar la expansión de la oferta de mano de obra para de esta forma evitar una contracción en los salarios. Por el contrario, Argentina mantuvo una apertura frente a la inmigración que derivó en un escenario de oferta excedente de mano de obra, el que permitió, como se dijo, una retracción del poder adquisitivo de las remuneraciones.

Los salarios reales en Estados Unidos y Canadá continuaron su ritmo expansivo, elevándose a una tasa anual acumulativa de 1.7 y $1.1 \%$, respectivamente, a lo largo de las primeras dos décadas del siglo xx, mientras esas economías crecían a un menor ritmo que Argentina. De este modo, se amplió la brecha entre los salarios relativos (véase gráfica 3) ${ }^{23}$ En tanto, los principales países de origen de los migrantes mantuvieron durante todo este periodo un nivel salarial sensiblemente más

\footnotetext{
${ }^{23}$ En Australia, en cambio, los salarios reales se contraen en el periodo, en una economía que ostenta un ritmo de expansión menor que el de los países mencionados.
} 
reducido que el vigente en Argentina, aunque la brecha de remuneraciones tendió a achicarse. 24 En promedio, entre 1900 y 1920 los salarios españoles se ubicaron $42 \%$ por debajo de los de Argentina y en el caso de Italia dicho diferencial alcanzó 40 por ciento.

La información publicada por la Comisión Económica para América Latina y el Caribe (CEPAL, 1959) da cuenta de la expansión de la oferta de trabajo en el periodo comprendido entre los años 1900 y $1930{ }^{25}$ Los trabajadores activos crecieron $23.4 \%$ en el periodo 1905-1909 respecto del quinquenio anterior, tasa que se mantuvo prácticamente inalterada en el lustro siguiente. Fue precisamente en 1910-1914 el periodo en que la expansión de la PEA resultó mayor en relación con el aumento del PIB: mientras la PEA creció $24.6 \%$, el producto aumentó $25.2 \%$ en el mismo periodo.

La sensible contracción de la actividad económica, como consecuencia de la primera guerra mundial, redujo el crecimiento de la población económicamente activa a 7 \% en 1915-1919. Finalmente, cuando se retomó la senda del crecimiento económico tras la guerra, el crecimiento de la oferta laboral resultó más moderado, tanto en términos absolutos como en relación a la expansión de la economía.

A su vez, la composición de los trabajadores activos por sector de actividad se modificó a lo largo de las primeras décadas del siglo xx, producto del menor dinamismo relativo del empleo agrario respecto a la industria, la construcción y los servicios. Mientras en el primer quinquenio del siglo xx, el sector agropecuario reunía $39.2 \%$ de los trabajadores activos, dicha proporción se redujo en forma prácticamente ininterrumpida hasta el abandono del modelo agroexportador a comienzos de la década de 1930, siendo de $35.9 \%$ en 1925-1929. El empleo agrario se expandió $96.6 \%$, entre el primer quinquenio del siglo xx y el segundo de la década de 1920, en tanto la industria y los servicios lo hicieron 124.7 y $127.8 \%$, respectivamente 26

No se puede dejar de mencionar la elevada movilidad que persistía en el mercado laboral, por lo cual la clasificación sectorial es sólo una aproximación a la realidad de cada sector. Pianetto (1984) sostiene que en 1914 cerca de 30 \% de la población masculina no calificada realizaba trabajos rurales en los periodos de cosecha para durante el resto del año trabajar en los centros urbanos, fundamentalmente en actividades de servicios y en la construcción.

En resumen, en la primera etapa (1870-1900), como se analizó, el flujo de migrantes habría sido insuficiente ante el incremento que verificó la demanda de mano de obra, proceso que se tradujo en un incremento de los salarios reales. En cambio, en esta segunda etapa el aumento de la inmigración habría determinado un exceso de oferta de mano de obra y, con ello, una reducción de los salarios.

En este sentido, Bunge (1985) afirmaba que el periodo comprendido entre los años 1892 y 1904 fue de migración insuficiente en relación con los requerimientos de mano de obra adicional ante la expansión del área sembrada. En este contexto, la política gubernamental estuvo orientada a aplicar con todo rigor la legislación de represión a la vagancia para, de esta forma, contribuir a la expansión de la oferta de mano de obra (Pianetto, 1984).

\footnotetext{
${ }^{24}$ En este periodo existe una recuperación de los salarios en Italia que se expandieron a una tasa anual acumulativa de $3.6 \%$ entre 1900 y 1920, mientras que en España se redujeron a una tasa de $2.4 \%$ anual entre estos mismos años.

${ }^{25}$ No se cuenta con datos previos a 1900 y la información se presenta agrupada en quinquenios.

${ }^{26}$ Para un análisis de los orígenes del proceso de industrialización en Argentina a lo largo del modelo agroexportador se puede consultar Villanueva (1972).
} 
Por el contrario, en la segunda de las etapas analizadas, Bunge (1985) afirma que se produjo desde 1906 una oferta excedente de mano de obra que se extendió hasta 1911, cuando por un marcado descenso de la actividad de la construcción se transformó en desocupación. Según este autor "después de 1910 el país no está en condiciones de absorber ni siquiera el crecimiento vegetativo de la población trabajadora" ${ }^{27}$ La reducción de los salarios reales y el aumento del desempleo se profundizó en el marco de la fuerte contracción que experimentó la economía durante la primera guerra mundial, proceso que se exacerbó por una magra cosecha que tuvo lugar durante la campaña 1916-1917 ${ }^{28}$ La desocupación alcanzó sus niveles máximos en 1916 y 1917, alcanzando a $19 \%$ de la población económicamente activa (Bunge, 1929) Este deterioro en el mercado de trabajo condujo a la reversión de los flujos migratorios entre los años 1914 y 1918 , cuando más de 100000 trabajadores abandonaron Argentina en términos netos.

Tras el fin de la primera guerra mundial, la recuperación del comercio y de los precios internacionales permitió retomar nuevamente el sendero del crecimiento económico. A diferencia del periodo previo, y en el contexto de una disminución relativa en los flujos migratorios (especialmente en términos netos), se asistió a una recuperación de los salarios reales que crecieron a una tasa anual acumulativa de $6.7 \%$. El crecimiento de las remuneraciones permitió superar los niveles prevalecientes a comienzos del siglo xx en 1922, para posteriormente continuar su ritmo ascendente hasta 1929 cuando comenzaron a manifestarse los primeros signos de la crisis internacional (véase gráfica 1).

A pesar del crecimiento que experimentaron los salarios reales durante esta tercera etapa, a finales de la década de los veinte, específicamente en 1929, Argentina poseía un nivel salarial inferior al verificado en la mayor parte de los países atractores de mano de obra. En efecto, los salarios australianos eran $27.6 \%$ mayores que los argentinos, los canadienses eran $16.2 \%$ más altos y los estadunidenses $65.7 \%$ mayores (véase gráfica 4). Argentina aún mantenía un salario real notoriamente más elevado que el vigente en Italia y España, países en los que la remuneración media era 61 y $51.4 \%$ más reducida, respectivamente.

\footnotetext{
${ }^{27}$ La publicación del Departamento Nacional del Trabajo (1916) afirmaba: "el país ha sostenido desde 1907 mayor número de brazos que el necesario para su actividad [...] La constatación de aquel exceso de brazos y de estas deficiencias y el estudio de sus resultados nos indujo aconsejar [...] juntamente con el esfuerzo de organización de la distribución del trabajo, la restricción y selección de la inmigración. Tal restricción se ha producido automáticamente en lo que va del año. Esto no ha sido suficiente, sin embargo, para equilibrar por completo el aumento de la oferta de trabajo." A partir de este tipo de evidencias, Beccaria $(2006$, p. 18) sostiene que, a pesar del rápido crecimiento del PIB y del empleo, el aumento de la inmigración habría implicado la aparición de "signos de oferta excedente de trabajo desde mediados de la primera década del siglo y hasta la guerra [...] Quizás también se registraba algún grado de subocupación encubierta que se manifestaba, por ejemplo, en la presencia de actividades terciarias que podrían calificarse como 'redundantes." Panettieri (1990), por su parte, expresa que la estacionalidad del empleo, así como su asociación al ciclo económico eran preocupaciones hacia 1910, al punto que se impulsó la realización de un estudio acerca de "La inseguridad de la vida obrera (informe sobre el paro forzoso)" (Gálvez, 1913, citado en Panettieri, 1990). También Sansoni (1990) documenta las pésimas condiciones de trabajo en las tareas agrarias, así como la característica estacionalidad de estas tareas, que dejaban a los trabajadores sin ocupación durante algunos meses. En el caso de los trabajadores golondrina, regresaban a sus países de origen en la época de baja actividad.

${ }^{28}$ La producción de cereales y oleaginosas en la campaña 1916-1917 se redujo casi $60 \%$ respecto de la campaña previa.

${ }^{29}$ En esos años, tal como afirma Pianetto (1984, p. 305) “masas de desocupados recorren las zonas agrarias asaltando trenes y negocios de comestibles, robando reses, mientras en las ciudades se improvisan 'ollas populares' con la colaboración privada y pública para paliar la situación”.
} 
La recuperación de los salarios reales a lo largo de esta última etapa habría sido facilitada por la desaceleración de los flujos migratorios netos, así como por la emigración neta durante la guerra (véase gráfica 3). A su vez, el peso relativo de la migración sobre la oferta de mano de obra fue perdiendo paulatinamente relevancia ante el crecimiento que experimentó la población a lo largo de todo este periodo ${ }^{30} \mathrm{El}$ hecho de que la tasa de radicación de la población migrante en estos años haya sido superior a la verificada con anterioridad da cuenta también de la existencia de mayores y mejores posibilidades de empleo y obtención de ingresos.

Sin embargo, la recuperación de los salarios en esta última etapa sólo compensó parcialmente el estancamiento y contracción experimentada en las primeras décadas del siglo xx. Los salarios reales se habían elevado sólo $13 \%$ en 1930 respecto a comienzos del siglo, en tanto la economía se había expandido $275.3 \%$ y el PIB per cápita en $48 \%$. Por lo tanto, al final del periodo se había verificado una importante pérdida de participación de la masa salarial en el producto.

\section{Conclusiones}

La economía argentina a lo largo del modelo agroexportador alcanzó el periodo de mayor crecimiento económico de su historia, significativamente elevado también en términos internacionales, incluso superando a países con una inserción en el mercado mundial similar como Australia y Canadá. Sin embargo, dicho crecimiento económico no se tradujo en un incremento análogo de las remuneraciones reales de los trabajadores, las cuales se expandieron a una tasa anual acumulativa de $1.1 \%$ entre 1870 y 1930 . Dicho crecimiento estuvo por debajo del experimentado por el PIB (5.2\%), pero también del PIB per cápita que creció a una tasa anual acumulativa de $1.9 \%$ entre esos años. De esta forma, el crecimiento de la economía fue profundizando una estructura social claramente inequitativa que eclosionará a mediados de los años 1940 con el advenimiento del peronismo al poder, proceso que generará una aguda redistribución del ingreso entre trabajo y capital.

A lo largo del trabajo se pudo observar que el retraso relativo de los salarios reales respecto del producto tuvo lugar principalmente en los primeros años posteriores al inicio del siglo xx y se profundizó durante la recesión económica con elevada desocupación que fue contemporánea a la primera guerra mundial. Esta desfavorable evolución se relacionó con un exceso de oferta de trabajo frente al cual no existió reacción por parte de la política pública. A diferencia de otros países con patrones de crecimiento con características similares al de Argentina en esos años, en el país primaron durante todo el periodo los intereses económicos de la burguesía agraria dedicada a la producción para el mercado externo, que pugnaba por la contención del poder adquisitivo del salario 31

\footnotetext{
${ }^{30} \mathrm{Al}$ respecto, Beccaria (2006, p. 19) afirma: "En la segunda parte de la década continuó una muy leve tendencia alcista. Esta elevación del nivel de los sueldos y salarios podría estar asociada a un ritmo de crecimiento de la oferta laboral -básicamente, de la población- que, si bien volvió a alcanzar niveles elevados luego de finalizada la guerra, resultó inferior a la registrada entre 1905 y 1914."

${ }^{31}$ La discusión acerca de las características y relevancia de la burguesía agraria durante este periodo supera los alcances del presente trabajo. Para un análisis detallado, pueden consultarse Arceo (2003) y Díaz (1975).
} 
Así, en un contexto de elevadas tasas de crecimiento económico y de empleo, la ampliación constante de la oferta de trabajo mediante el flujo de migración transoceánica permitió aumentar la competencia entre los trabajadores y de esta forma reducir los salarios reales. Este resultado se tradujo en una elevación de la tasa de ganancia, tanto de las fracciones del capital agrario como industrial y de servicios.

La contención de los salarios reales no sólo condicionó la estructura distributiva durante dicho periodo sino que condicionó la evolución futura de la economía argentina durante la etapa de industrialización por sustitución de importaciones, en tanto la masa de excedente generado por el sector agropecuario pampeano resultaría insuficiente para lograr una transferencia de recursos que posibilitara simultáneamente el sostenimiento de la expansión agropecuaria, el desarrollo industrial y la mejora en las condiciones de vida de la clase trabajadora.

\section{LISTA DE REFERENCIAS}

Arceo, E. O. (2003). Argentina en la periferia próspera: renta internacional, dominación oligárquica y modo de acumulación. Bernal: Universidad Nacional de Quilmes Ediciones.

Argentina. Departamento Nacional del Trabajo (1916). Anuario estadístico del trabajo, 1914. Boletin del Departamento Nacional del Trabajo, 33.

Ashworth, W. (1979). Breve historia de la economía internacional desde 1850. Madrid: Fondo de Cultura Económica.

Beccaria, L. (2006). El mercado de trabajo argentino en el largo plazo: los años de la economía agroexportadora. Buenos Aires: Comisión Económica para América Latina y el Caribe.

Bértola, L. y Ocampo, J. A. (2010). Desarrollo, vaivenes y desigualdad. Una historia económica de América Latina desde la Independencia. Argentina: Secretaría General Iberoamericana. Recuperado de https://www.segib.org/wp-content/uploads/Historia-Economica-AL-ESP.pdf

Bunge, A. (1929). Editorial. Revista de Economía Argentina, 11(127).

Bunge, A. (1985). Las relaciones comerciales entre Argentina y Estados Unidos. En J. J. Llach (ed.), La Argentina que no fue (vol. 1, pp. 105-109). Buenos Aires: Instituto de Desarrollo Económico Social.

Caruana, P. (2015). Mediterranean labor markets in the first age of globalization an economic history of real wages and market integration. Basingstoke: Palgrave Macmillan.

Chiaramonte, J. C. (1971). Nacionalismo y liberalismo económicos en Argentina: 1860-1880. Buenos Aires: Hyspamérica.

Comisión Económica para América Latina y el Caribe (1959). El desarrollo económico de la Argentina. Buenos Aires: Autor. Recuperado de https://repositorio.cepal.org/handle/11362/9007

Cortés, R. (1963). Problemas del crecimiento Industrial de la Argentina (1870-1914). Desarrollo Económico, 3(1-2), 143-171. DOI: $10.2307 / 3465953$

Cortés, R. (1979). El progreso argentino, 1880-1914. Buenos Aires: Editorial Sudamericana.

Cortés, R. (1998). La economía de exportación de Argentina, 1880-1920. Anuario IEHS, 13, 27-76.

Devoto, F. J. (2004). Las políticas migratorias de Francia y Argentina en el largo plazo. Estudios Migratorios Latinoamericanos, 18(53), 121-153.

Díaz, C. (1975). Ensayos sobre la historia económica argentina. Buenos Aires: Amorrortu.

Ferreres, O. J. (ed.) (2010). Dos siglos de economía argentina: 1810-1910-2010: historia argentina en cifras. Buenos Aires: El Ateneo. 
Ford, A. G. (1969). Argentina y la Crisis de Baring de 1890. Revista de Economía y Estadística, 13(3-4), 133-167.

Green, A. G. y Green, D. A. (1999). The Economic Goals of Canada's Immigration Policy: Past and Present. Canadian Public Policy/Analyse de Politiques, 25(4), 425-451. DOI: $10.2307 /$ 3552422

Green, A. G. y Green, D. A. (2004). The goals of Canada's immigration policy: a historical perspective. Canadian Journal of Urban Research, 13(1), 102-139.

Hatton, T. J. y Williamson, J. G. (1998). The age of mass migration causes and economic impact. Nueva York: Oxford University Press.

Hobsbawm, E. (1998). La era del imperio, 1875-1914. (J. Faci Lacasta, Trad.). Buenos aires: Crítica/Grijalbo/Mondadori.

Husband, W. W. (1922). Immigration Under the Per Centum Limit Act. Monthly Labor Review, 15(2), 1-10.

Kelley, A. C. (1965). International Migration and Economic Growth: Australia, 1865-1935. The Journal of Economic History, 25(3), 333-354. DOI: 10.1017/S0022050700057351

Lattes, A. E. (1985). Migraciones hacia América Latina y el Caribe desde principios del siglo XIX (vol. 35). Recuperado de http://www.cenep.org.ar/index.php/publicaciones-del-cenep/cuader nos-del-cenep

Maddison, A. (2010). Statistics on world population, GDP and per capita GDP, 1-2008 AD. Países Bajos: Groningen Growth and Development Centre/University of Groningen. Recuperado de https://www.rug.nl/ggdc/historicaldevelopment/maddison/releases/maddison-projectdatabase-2018

Míguez, E. J. (2001). El mercado de trabajo y las estrategias de los migrantes en el flujo transatlántico de mano de obra hacia la Argentina. Un panorama. Estudios Migratorios Latinoamericanos, 16(49), 443-468.

Novick, S. (1989). Ley y población en la sociedad argentina, 1870-1986 (Tesis de maestría). Facultad Latinoamericana de Ciencias Sociales, Buenos Aires.

Otero, H. (2006). Estadística y nación: una historia conceptual del pensamiento censal de la Argentina moderna, 1869-1914. Buenos Aires: Prometeo.

Otero, H. (2012). La guerra en la sangre: los franco-argentinos ante la Primera Guerra Mundial. Buenos Aires: Sudamericana.

Panettieri, J. (1970). Inmigración en la Argentina. Macchi. Buenos Aires.

Panettieri, J. (1990). Desocupación, subocupación, trabajo estacional, trabajo intermitente. De la crisis del '90 a la primera guerra mundial. En J. Panettieri (ed.), Mercado de trabajo y paro forzoso: desde los comienzos de la Argentina moderna hasta la crisis de los años '30. (vol. 1, pp. 7-38). La Plata: Universidad Nacional de La Plata. Recuperado de http://www.memoria.fahce.unlp.edu.ar/lib ros/pm.96/pm.96.pdf

Pianetto, O. (1984). Mercado de trabajo y acción sindical en la Argentina, 1890-1922. Desarrollo Económico, 24(94), 297-307. DOI: 10.2307/3466742

Recchini de Lattes, Z. L. y Latter, A. E. (1975). La población de Argentina. Buenos Aires: Instituto Nacional de Estadísticas y Censos de la República Argentina. Recuperado de http://biblio.econ. uba.ar/cgi-bin/koha/opac-detail.pl?biblionumber=121186

Rocchi, F. (2000). El péndulo de la riqueza: la economía argentina en el periodo 1880-1916. En M. Z. Lobato (ed.), Nueva historia argentina: 5. El progreso, la modernización y sus límites 18801916 (pp. 15-69). Buenos Aires: Sudamericana. 
Sánchez-Alonso, B. (2004). Algunas reflexiones sobre las políticas de inmigración en América Latina en la época de las migraciones de masas. Estudios migratorios latinoamericanos, 18(53), $155-176$.

Sansoni, M. (1990). Mercado de trabajo agrícola y el paro estacional en el Agro Pampeano (18901920). En J. Panettieri (ed.), Mercado de trabajo y paro forzoso: desde los comienzos de la Argentina moderna hasta la crisis de los años '30. (vol. 2, pp. 7-37). La Plata: Universidad Nacional de La Plata. Recuperado de http://www.memoria.fahce.unlp.edu.ar/libros/pm.96/pm.96.pdf

Solimano, A. (2004). Globalization, History and International Migration: A View from Latin America (Working Paper). Ginebra: International Labour Office. Recuperado de http://www.ssrn.com/ abstract $=908241$

Tato, M. I. (2011). El llamado de la patria. Británicos e italianos residentes en la Argentina frente a la Primera Guerra Mundial. Estudios migratorios latinoamericanos, 25(71), 272-292.

Torrado, S. (2003). Historia de la familia en la Argentina moderna. Bueno Aires: Ediciones de la Flor.

Vázquez, V. (1971). Estadisticas historicas argentinas (comparadas): primera parte 1875-1914. Buenos Aires: Macchi.

Villanueva, J. (1972). EL origen de la industrialización argentina. Desarrollo Económico, 12(47), 451-476. DOI: $10.2307 / 3466076$

Willcox, W. F. (1929). International Migrations, Volume I: Statistics. Cambridge: National Bureau of Economic Research. Recuperado de https://papers.nber.org/books/fere29-1

Williams, J. H. (1920). Argentine international trade under inconvertible paper money, 1880-1900. Cambridge: Harvard University Press.

Williamson, J. G. (1995). The Evolution of Global Labor Markets since 1830: Background Evidence and Hypotheses. Explorations in Economic History, 32(2), 141-196. DOI: 10.1006/exeh. 1995.1006 